\title{
The impact of preparation route on the performance of silver dodecatungstophosphate/ $\beta$ zeolite catalysts in the ethylene production
}

\author{
Dejana Janićijević ${ }^{1}$ Snežana Uskoković-Marković ${ }^{2}$ - Alexandru Popa ${ }^{3}$ - Bojana Nedić Vasiljević1 - Anka Jevremović ${ }^{1}$. \\ Maja Milojević-Rakić ${ }^{1}$ Danica Bajuk-Bogdanović ${ }^{1}$ (I)
}

Received: 8 December 2020 / Accepted: 3 February 2021 / Published online: 20 February 2021

(c) Institute of Chemistry, Slovak Academy of Sciences 2021

\begin{abstract}
Heteropolyacids and their salts comprise catalytic centers for the production of ethylene, one of the most important constituents in the chemical industry. The paper emphasizes different synthesis routes of hybrid materials consisting of dodecatungstophosphoric acid silver salt (AgPW) and $\beta$ zeolite—stepwise wet impregnation, silver-exchange in $\beta$ zeolite, and dry mixing of precursors. Composite preparation procedures induced minor effects on the weak acid sites, while strong acid sites were increased significantly. $\beta / \mathrm{AgPW}$ composites prepared by two-steps wet impregnation and ion-exchange procedures have strong acid sites content and total acidity higher in comparison to the pure AgPW salt and $\beta$ zeolite. This is a result of precursors synergetic effect—cumulative strong acidic sites are generated in the presence of well-dispersed Keggin ions on the zeolite network. Composite samples with a higher content of strong acid centers exhibit higher conversion in the ethanol dehydration reaction, i.e., the ion-exchanged $\beta \mathrm{AgPW}$ sample has attained a conversion over $81 \%$, while the wet-impregnated sample has a significant $86 \%$. The distribution and presence of AgPW active phase are found to be crucial for both stable conversion and high selectivity results in ethylene production from ethanol, which is regarded as one of the most significant processes in environmental and sustainable industrial chemistry.
\end{abstract}

\section{Graphic abstract}

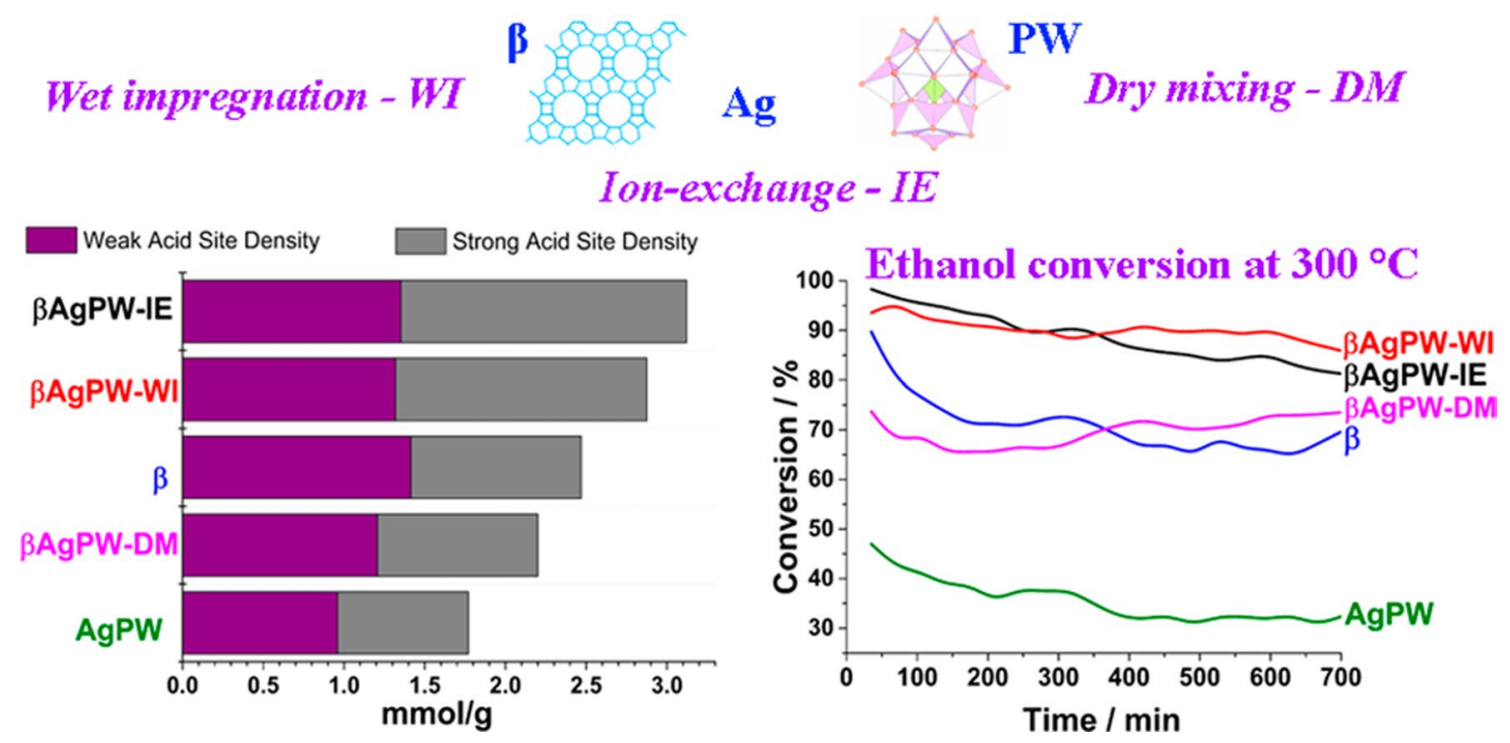

Keywords Beta zeolite $\cdot$ Silver dodecatungstophosphate $\cdot$ Composite samples $\cdot \mathrm{NH}_{3}$-TDP $\cdot$ Ethanol dehydration

Extended author information available on the last page of the article 


\section{Introduction}

Ethylene has one of the largest yields in the field of petrochemical products worldwide and is recognized as one of the key constituents in the chemical industry. Approximately three-quarters of products obtained in the petrochemical industry are ethylene-based. Moreover, ethylene is a monomer in a whole range of polymerization processes for plastics production (Zhang and Yu 2013). Ethylene production through catalytic dehydration of alcohols is more economically reasonable then ethylene production from petroleum. A coherent strategy for catalysts preparation that is employed in selective alcohols conversion to olefins is fundamental, as there is a competitive reaction with etherification products. Austin et al. (2018) reported that silver-containing metal oxide clusters with structural curvature show unfavorable etherification chemistries while favoring the olefin production. Thus, catalysts containing strong Lewis acid sites are found to be highly active and selective in aforesaid reactions.

It is known that heteropolyacids and their salts comprise catalytic centers for ethanol dehydration-Lewis and Brønsted acid sites, where Brønsted acids are efficient at lower temperatures (Gallo et al. 2014). When the pristine silver salt of dodecatungstophosphoric acid, $\operatorname{Ag}_{3} \mathrm{PW}_{12} \mathrm{O}_{40}$ (AgPW) is investigated, the catalyst was found to be highly efficient and selective for ethylene production (Matachowski et al. 2012). There is, however, a question of catalyst stability at a given reaction temperature, with partial or substantial solubility, which is often noted as an obstacle for heteropolyacids and related compounds applications (Gallo et al. 2014). Many aluminosilicate compounds are assessed as commercial-grade catalysts for dehydration reaction, among which zeolites are often part of the research targets (Madeira et al. 2009; Ramasamy and Wang 2014; Jović et al. 2017; Clemente et al. 2019). If the aim is to combine two excellent catalytic materials, can enhanced catalytic performance be expected? Systematic upgrade of zeolites with organic and inorganic active phase molecules and structures has proved to be a valuable approach for manufacturing upgraded materials for various environmental applications (Milojević-Rakić et al. 2013, 2018; Jović et al. 2017, 2018; Bajuk-Bogdanović et al. 2017; Jevremović et al. 2019, 2020). MFI zeotype excels by far in this catalysts search, but the present study aims to show that BEA zeotype $(\beta)$ with larger pores and higher acid stability may be a better choice for ethanol dehydration. Superb adsorption and catalytic performances have already been established for $\beta$ based hybrid materials, but an important improvement of considered materials lies especially in silver ion introduction. Antimicrobial activity of silver incorporated in heteropolyacid/zeolite materials was proved recently (Janićijević et al. 2020) which extended their usual application as efficient adsorbents (Bajuk-Bogdanović et al. 2017; Nedić Vasiljević et al. 2019). The idea behind the design of these materials lies in the ease of synthesis and fine-tuning of preparation procedures that can influence success in targeted applications, particularly in the field of environmental science. Spectroscopic analysis of AgPW active phase interaction with zeolite structure demonstrated the uniform distribution of active sites, which proved to be of utmost importance for pollutants adsorption. As active sites distribution and strength are essential for catalysis, for which adsorption is a required initial stage in heterogeneous catalysis, we expect that these hybrid materials will be highly efficient catalysts. That is why this contribution is dealing with ethanol dehydration, as it is regarded as one of the key processes in environmental and sustainable industrial chemistry.

Hybrid materials consisting of $\beta$ zeolite and $\mathrm{AgPW}$ were prepared with varying synthesis strategies. Different characterization methods were employed to investigate active centers in view of catalytic performance: infrared spectroscopy (FTIR), atomic force microscopy (AFM), thermogravimetry (TG), and ammonia temperature-programmed desorption. So far, this is the first contribution of silver tungstophosphate/zeolite hybrid materials in the catalytic dehydration of ethanol.

\section{Experimental}

\section{Materials}

Zeolite $\beta$ ( $\mathrm{Si} / \mathrm{Al}$ mole ratio is 12.5 ; in an ammonium form, and designated with a specific surface of $680 \mathrm{~m}^{2} \mathrm{~g}^{-1}$ ) was purchased from Zeolyst International. Thermal treatment for $5 \mathrm{~h}$ at $550{ }^{\circ} \mathrm{C}$ transformed zeolite into its hydrogen form $(\mathrm{H} \beta)$ (Kunkeler et al. 1998). H $\beta$ zeolite was subjected to an ion-exchange procedure using silver-nitrate (Centrohem, Serbia) to obtain silver ion in zeolite extra-framework positions $(\operatorname{Ag} \beta)$. The sample was filtered, washed, and dried for $3 \mathrm{~h}$ at $110^{\circ} \mathrm{C}$.

12-Tungstophosphoric acid, $\mathrm{H}_{3}\left[\mathrm{PW}_{12} \mathrm{O}_{40}\right] \cdot 6 \mathrm{H}_{2} \mathrm{O}$, denoted as HPW, was synthesized in agreement with the literature (Rosenheim and Jaenicke 1917; De Oliveira et al. 2014). The obtained hexahydrate sample was kept in a desiccator with silica gel before measuring mass. Further on, a silver salt of HPW (AgPW) was prepared through a titration procedure, and the sample was formed by evaporation at $110^{\circ} \mathrm{C}$ and calcination at $300{ }^{\circ} \mathrm{C}$.

The detailed sample preparation procedure was given previously (Janićijević et al. 2020). Briefly, hybrid materials were prepared at a fixed AgPW mass fraction of $20 \mathrm{wt} \%$, 
but in varying synthesis procedures-wet impregnation in two steps, Ag ion-exchange, and dry mixing, denoted to as procedures WI, IE, and DM, in that order.

WI method-a solution of $\mathrm{AgNO}_{3}$ was mixed with $\mathrm{H} \beta$ in suspension for the first $2 \mathrm{~h}$ and then left to age for $24 \mathrm{~h}$. The second step comprised the addition of HPW, followed by stirring, aging, evaporation, and calcination at $300{ }^{\circ} \mathrm{C}$. The sample obtained in this way was marked as $\beta \mathrm{AgPW}-\mathrm{WI}$.

IE method-Ag $\beta$ sample was mixed with $0.1 \mathrm{M}$ HPW (solution volume was chosen to gain $\mathrm{H} \beta / \mathrm{AgPW}$ mass ratio of 4). The suspension was subjected to stirring, aging, evaporation, and calcination at $300{ }^{\circ} \mathrm{C}$. The sample obtained in this way was marked as $\beta \mathrm{AgPW}$-IE.

DM method-analogous to the two mentioned methods, certain quantities of $\mathrm{H} \beta$ and pre-prepared $\mathrm{AgPW}$ (in mass ratio 4) were mixed solvent-free, in a mortar with a pestle and calcinated at $300{ }^{\circ} \mathrm{C}$. The sample was marked as $\beta$ AgPW-DM.

\section{Methods}

Atomic force microscopy (AFM) was performed on NTEGRA Prima microscope (NT-MDT Spectrum Instruments) in tapping-mode. Samples were arranged in the form of a thin layer by air-drying after preparation of water dispersion, in ambient conditions. An AFM probe consisting of N-type doped silicon coated with aluminum with $3.5 \mathrm{~N} \mathrm{~m}^{-1}$ force constant, and $75 \mathrm{kHz}$ resonant frequency was employed. Scanning resolution was 512 data points per scan and operating program Nova Px with the included ScanT module was used. Data Processing P9 software was applied for image analysis.

The FTIR spectra were recorded on a Nicolet iS20 FT-IR spectrophotometer with 64 scans and $2 \mathrm{~cm}^{-1}$ resolution.

Thermogravimetric analysis (TG) and differential thermal analysis (DTA) of prepared hybrid materials were executed on an TA SDT 2690 microbalance, with $90-\mu \mathrm{L}$ platinum sample pans. Samples were stored at 23\% relative humidity before measurement. Heating was performed in the $25-750{ }^{\circ} \mathrm{C}$ range with $10{ }^{\circ} \mathrm{C} \mathrm{min}^{-1}$ rate, in the air atmosphere.

Temperature-programmed desorption of ammonia (TPD- $\mathrm{NH}_{3}$ ) was carried out with an instrument used for thermal analysis: Mettler TGA/SDTA 851/LF/1100 thermo analyzer. The thermal analysis system was coupled with a Pfeiffer-Vacuum-Thermo Star mass spectrometer by silica capillary at a temperature of $473 \mathrm{~K}$. About $20 \mathrm{mg}$ samples were used for measurements in stainless steel crucibles of $150 \mu \mathrm{L}$

Before TPD studies at $373 \mathrm{~K}$, the sample was treated at $573 \mathrm{~K}$ for $15 \mathrm{~min}$ by passing pure air and then cooling from 573 to $373 \mathrm{~K}$, under nitrogen flow (step 1). After pre-treatment, a stream of $50 \mathrm{~mL} \mathrm{~min}^{-1}$ consisting of nitrogen and
$\mathrm{NH}_{3}$ and $\mathrm{H}_{2} \mathrm{O}$ vapors (obtained by passing the nitrogen over $25 \mathrm{wt} . \%$ ammonia solution at room temperature) was blown over solid sample until its constant weight was reached (75 min) (step 2). Subsequently, the sample was flushed with nitrogen for $45 \mathrm{~min}$ at the same temperature to remove physisorbed ammonia (step 3 ). The ammonia desorption is followed by non-isothermal heating from 373 to $873 \mathrm{~K}$ at $10 \mathrm{~K} \mathrm{~min}^{-1}$, under $\mathrm{N}_{2}$ flow $\left(50 \mathrm{~mL} \mathrm{~min}^{-1}\right)$ (step 4). TPD of ammonia was employed to measure the amount and strength of the acidic sites of the samples. The strength of acid sites is related to the corresponding desorption temperature. The amount of $\mathrm{NH}_{3}$ evolved was calculated from the mass loss of the samples observed on TG curves. First, the mass losses associated with water and ammonia desorption from the acid sites were determined. Then, the second experiment of adsorption-desorption of water was done. The subtraction of the normalized masses [Sample with ammonia (solution of $25 \% \mathrm{NH}_{3}$ in water) - Sample with water] gives the adsorbed ammonia on the solid sample. Each mass loss related to desorption of ammonia from acid sites was converted to express the number of millimoles of ammonia adsorbed on such sites per millimole of an anhydrous sample.

\section{Catalytic test}

The catalytic activities of the samples were tested for vapor phase ethanol dehydration reaction under atmospheric pressure at $300{ }^{\circ} \mathrm{C}$. A differential tubular stainless steel flow reactor placed into a tubular furnace was used. Typically $100 \mathrm{mg}$ of the catalyst was placed in the middle of the reactor supported by quartz from both ends. Liquid ethanol was pumped by a syringe pump at a flow rate of $1.2 \mathrm{~mL} \mathrm{~h}^{-1}$ into the evaporator (heated to $150{ }^{\circ} \mathrm{C}$ ) where it was mixed with nitrogen and air at a ratio of EtOH: $\mathrm{N}_{2}: \mathrm{O}_{2}=1: 3.5: 0.4$. The total flow rate of the vapor stream was kept constant at $30 \mathrm{~mL} \mathrm{~min}{ }^{-1}$. The products were analyzed using a Hewlett Packard 5890 GC gas chromatograph equipped with a flame ionization detector (FID) and Porapak QS column. A typical space velocity (WHSV) of $9.5 \mathrm{~h}^{-1}$ (grams of ethanol per hour per gram of catalyst) was calculated at $298 \mathrm{~K}$.

\section{Results and discussion}

\section{AFM surface morphology investigation}

The AFM technique was carried out to investigate the surface morphology of prepared samples. The three-dimensional images with a scan area of $10 \times 10 \mu \mathrm{m}$ for the precursors $\beta$ zeolite and $\mathrm{AgPW}, 3 \times 3 \mu \mathrm{m}$ for the $\beta \mathrm{AgPW}-\mathrm{WI}$, and $5 \times 5 \mu \mathrm{m}$ for the $\beta A g P W-I E$ are presented in Fig. 1 .

The AFM picture of AgPW shows aggregates of irregular cubic and dodecahedron shape with average sizes about 

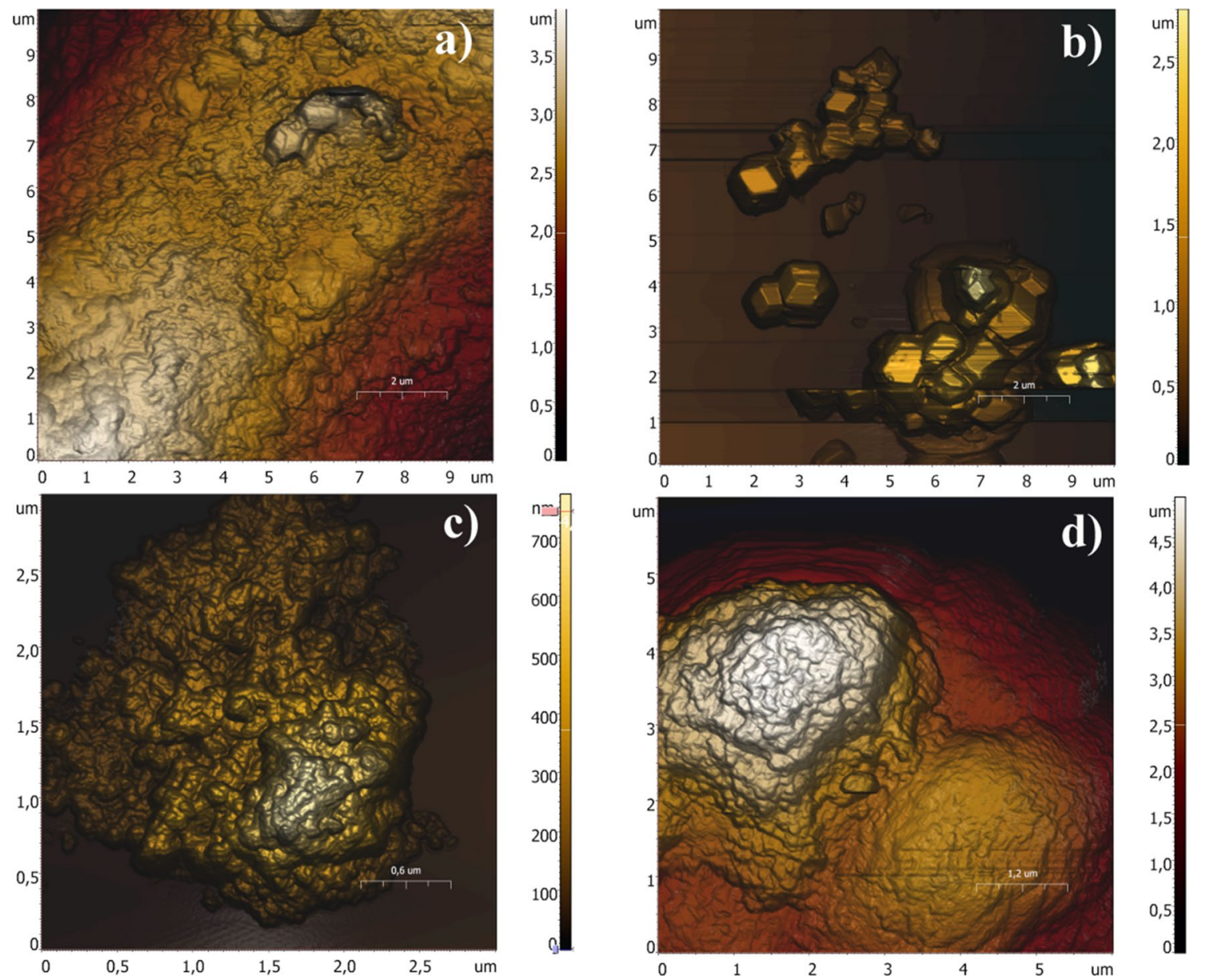

Fig. 1 AFM images of precursors and composites: a $\beta$ zeolite, b AgPW, $\mathbf{c} \beta$ AgPW-WI and $\mathbf{d} \beta$ AgPW-IE

$500 \mathrm{~nm}$. The morphology of the particles of heteropoly salts depends on counter-ions, temperature, aging and other experimental procedures applied during the synthesis (Okamoto et al. 2007). On the other hand, for $\beta$ zeolite, it is obvious that the surface is composed of rugged layers. As one can see from Fig. 1c, d, composites that were made according to the two-step wet impregnation and ion-exchange procedures have comparable surface characteristics as pristine $\beta$. The results show that in these samples, AgPW salt is homogeneously dispersed on the surface of the $\beta$ zeolite without visible large salt agglomerates in the samples.

\section{FTIR}

Figure 2a shows FTIR spectra of the AgPW salt. The set of peaks observed between 1080 and $524 \mathrm{~cm}^{-1}$ originates from the bands associated with metal-oxygen skeletal modes of the Keggin unit. The bands at 1080, 983, 888 and $808 \mathrm{~cm}^{-1}$, correspond to asymmetric stretching vibrations, $\left(\mathrm{P}-\mathrm{O}_{\mathrm{a}}\right)$, $\left(\mathrm{W}=\mathrm{O}_{\mathrm{d}}\right),\left(\mathrm{W}-\mathrm{O}_{\mathrm{b}}-\mathrm{W}\right)$ and $\left(\mathrm{W}-\mathrm{O}_{\mathrm{c}}-\mathrm{W}\right)$, respectively, while the bands at 594 and $524 \mathrm{~cm}^{-1}$ originate from deformation asymmetric $\left(\mathrm{O}_{\mathrm{a}}-\mathrm{P}-\mathrm{O}_{\mathrm{a}}\right)$ vibrations (Rocchiccioli-Deltcheff et al. 1983; Ratajczak et al. 2001). The deformation band of non-protonated water at $1618 \mathrm{~cm}^{-1}$ and bands at 3520 and $3471 \mathrm{~cm}^{-1}$ in the region of the stretching $(\mathrm{O}-\mathrm{H})$ vibrations are weak, in accordance with the low degree of hydration of the calcined sample.

The FTIR spectra of $\beta$ (Fig. 2e) exhibit a band characteristic for isolated bridging hydroxyl groups $(\mathrm{Si}-\mathrm{O}(\mathrm{H})-\mathrm{Al}$, Brønsted type acid site) at $3644 \mathrm{~cm}^{-1}$ and bands attributed to physically adsorbed water, at 3447 with a shoulder at $3212 \mathrm{~cm}^{-1}$, and at $1635 \mathrm{~cm}^{-1}$ (Van Bekkum et al. 2001). In addition to these bands, vibrational frequencies of internal tetrahedra of the $\beta$ zeolite lattice are observed at 1228 and $1089 \mathrm{~cm}^{-1}$ (asymmetric stretching vibration) and the band at around $789 \mathrm{~cm}^{-1}$ (symmetric stretching vibration). Also, the bands at 618,572 and $520 \mathrm{~cm}^{-1}$ (external linkages, double ring modes), 460 and $428 \mathrm{~cm}^{-1}$ [internal tetrahedra, (T-O) bending vibration] are evident (Flanigen et al. 1974).

The bands of the $\beta$ precursor appear in the FTIR spectra of the composites, while the bands of the AgPW salt are barely visible in the spectra, due to the overlap with the 
Fig. 2 FTIR spectra in the $4000-400 \mathrm{~cm}^{-1}$ (left) and in the $1000-850 \mathrm{~cm}^{-1}$ (right) region of: a AgPW, b $\beta$ AgPW-WI, c $\beta A g P W-I E, d$ BAgPW-DM and e $\beta$ zeolite

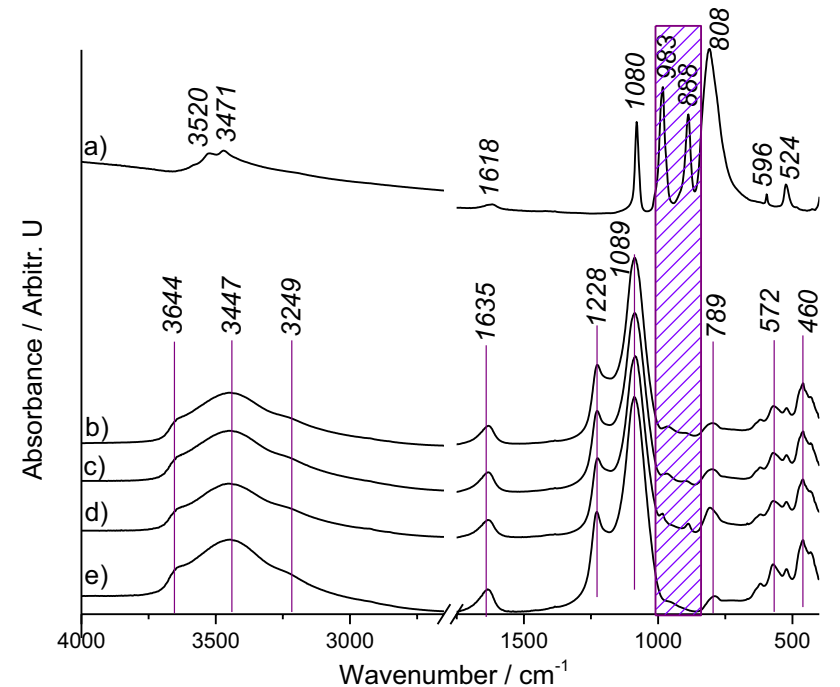

bands of the mass-dominant zeolite precursor. As can be seen from Fig. 2e (right) in the $1000-850 \mathrm{~cm}^{-1}$ region, $\beta$ has no pronounced bands, while AgPW (Fig. 2a) exhibits bands at $983\left(\mathrm{~W}=\mathrm{O}_{\mathrm{d}}\right)$ and $888 \mathrm{~cm}^{-1}\left(\mathrm{~W}-\mathrm{O}_{\mathrm{b}}-\mathrm{W}\right)$.

The spectrum of sample $\beta$ AgPW-WI (Fig. 2b) in the $\left(\mathrm{W}=\mathrm{O}_{\mathrm{d}}\right)$ vibration region possesses a broadened band at $962 \mathrm{~cm}^{-1}$. When compared to the spectrum of the AgPW sample, the $\mathrm{W}=\mathrm{O}_{\mathrm{d}}$ band is wider and red-shifted for $21 \mathrm{~cm}^{-1}$, indicating that the $\mathrm{W}=\mathrm{O}_{\mathrm{d}}$ bond is weaker in composites. The appearance of a shoulder on this band at $983 \mathrm{~cm}^{-1}$ which corresponds to $\left(\mathrm{W}=\mathrm{O}_{\mathrm{d}}\right)$ vibration in bulk $\mathrm{AgPW}$, where the primary Keggin units are linked to each other by hydrogen bonds, indicates the existence of Keggin anions which are not in direct contact with $\beta$ zeolite. The $\left(\mathrm{W}-\mathrm{O}_{\mathrm{b}}-\mathrm{W}\right)$ band is less intense than in AgPW and is blue-shifted for about $6 \mathrm{~cm}^{-1}$. The mentioned changes in the band positions suggest that Keggin anion distortion occurs as a consequence of the interaction between oxygen atoms in anion and extraframework cations, $\mathrm{H}^{+}$or $\mathrm{Ag}^{+}$, on the $\beta$ zeolite surface.

The spectrum of $\beta$ AgPW-IE (Fig. 2c) is very similar to the spectrum BAgPW-WI, but the band of $\left(\mathrm{W}=\mathrm{O}_{\mathrm{d}}\right)$ vibration of bulk AgPW is not present. This is an obvious indication that the Keggin anions are evenly distributed on the zeolite surface without agglomeration formation.

On the other hand, the spectrum of sample $\beta \mathrm{AgPW}-\mathrm{DM}$ (Fig. 2d) is different from the spectra of the other two composites, with the more intense two bands in this region with unchanged positions. This indicates that the applied procedure leaves the Keggin anions intact, i.e., that there is no interaction in the absence of solvents in the reaction mixture.

\section{TG/DTA}

A gradual loss of adsorbed and structural water molecules in the temperature range up to ca. $250{ }^{\circ} \mathrm{C}$ was formerly reported for HPW and its salts (Bajuk-Bogdanović et al. 2017; Nedić Vasiljević et al. 2019). As investigated composites aim to be anhydrous catalysts with preserved Keggin structure (Mioč et al. 2005; Bajuk-Bogdanović et al. 2017) and reactivity without water molecules shielding active sites, samples were subjected to calcination $300{ }^{\circ} \mathrm{C}$ during the preparation procedure.

The effect of the preparation procedure on the thermal stability of synthesized $\beta \mathrm{AgPW}$ composites was investigated and comparative results against starting components are given in Fig. 3.

The most complex thermal profile is observed for the AgPW sample, as there are two endo- and one exothermic peak. The endothermic events recorded for AgPW salt at 100 and $253{ }^{\circ} \mathrm{C}$ are assigned to physisorbed (mass loss of only $0.4 \mathrm{wt} . \%)$ and structural water loss ( $1.5 \mathrm{wt} . \%)$, in that order. This is in line with literature data, as it is known that the Ag salt is more stable than HPW itself as its structural water is released up to $100{ }^{\circ} \mathrm{C}$ (Holclajtner-Antunović et al. 2015a). When the AgPW curve is inspected, there is no deprotonation step over $400{ }^{\circ} \mathrm{C}$ that typically occurs for pure acid which is related to water molecules formed from loose hydrogens and oxygens in the Keggin structure. This is the evidence of complete, neutral salt formation in our preparation procedure. An exothermic process at $608{ }^{\circ} \mathrm{C}$ matches the transformation of the crystal structure to tungsten/phosphorus bronze phase (Mioč et al. 1994).

Thermal profiles for composite samples lie between those recorded for AgPW and $\beta$ zeolite. The minimum on the DTA curve shifts to higher temperatures in composite samples compared to pristine zeolite. These endothermic events point to changed hydrophilicity of composites as a result of a different distribution of AgPW active phase over zeolite surface. The sample $\beta$ AgPW-DM retained the lowest amount of water ( 7 wt. $\%)$, while $\beta$ AgPW-WI 

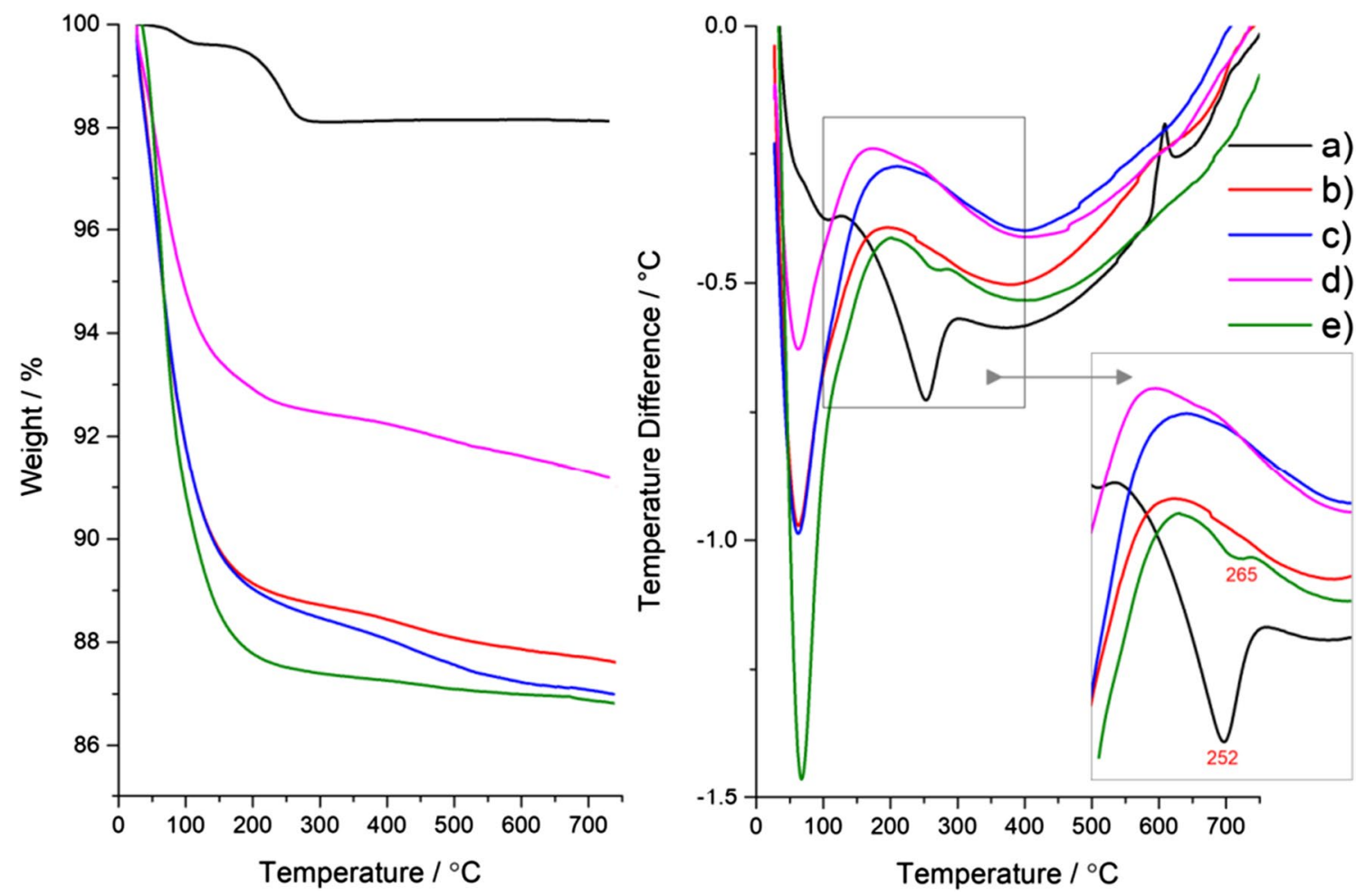

Fig. 3 TG (left) and DTA (right) results for: a AgPW, b $\beta$ AgPW-WI, $\mathbf{c} \beta$ AgPW-IE, $\mathbf{d}$ BAgPW-DM and e $\beta$ zeolite

and $\beta$ AgPW-IE have had higher moisture content before TG analysis, 12.6 and 13.2 wt.\%, in that order. Similar water content is found for $\beta$ zeolite ( $13 \mathrm{wt} . \%)$, while its comparison to composites thermal profile reveals the less gradual release of water molecules. The absence of the exothermic process at cca. $600{ }^{\circ} \mathrm{C}$ in the composites may be related to the increased thermal stability of the Keggin anion in AgPW/ $\beta$ materials.

The effect of AgPW phase distribution over the zeolite network in $\beta \mathrm{AgPW}-\mathrm{WI}$ and $\beta \mathrm{AgPW}$-IE composites did not affect significantly prevailing hydrophilicity of zeolite. On the other hand, a noticeable difference can be observed for the sample prepared by dry mixing, $\beta \mathrm{AgPW}-\mathrm{DM}$, where the thermal profile may suggest the existence of unsupported AgPW phase.

An intriguing finding is DTA peaks recorded at 252 and $265^{\circ} \mathrm{C}$ for $\mathrm{AgPW}$ and $\beta$ samples, in that order, which are missing in composite profiles. The explanation may lie in crystal water occluded in AgPW bulk phase as noted in TG results and analogous, existing water molecules in the zeolite cages. These active sites in both, AgPW and $\beta$, require higher temperature to be released in comparison to physisorbed water at the surface. After composites are prepared, there is no crystal water able to escape samples, as the zeolite surface is covered uniformly with AgPW (no bulk salt phase) blocking pore openings.

\section{TPD- $\mathrm{NH}_{3}$}

The ammonia adsorption-desorption technique was used for the determination of the amounts of acidic sites and the strength of acid sites present on the sample surface, together with the total acidity. The $\mathrm{NH}_{3}$-TPD experiments were recorded as TG/DTG and DTA curves. The various steps of a TGA-TPD experiment for AgPW salt conducted using ammonia base is shown in Fig. 4 (see

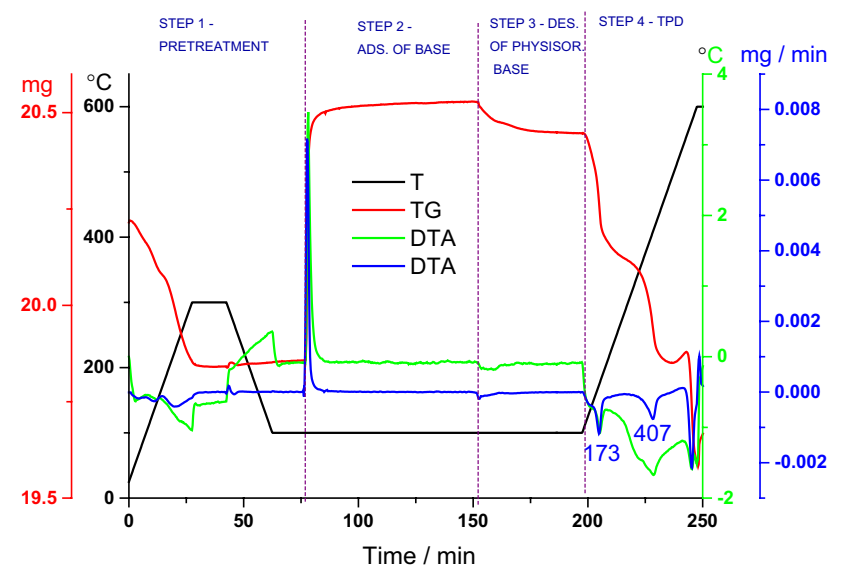

Fig. 4 The various steps of a TGA-TPD experiment for AgPW salt conducted using ammonia base (solution of $25 \% \mathrm{NH}_{3}$ in water) 
experimental part for details). This method was used previously by Sasca et al. (2010) for studying the acidities of 12-tungstophosphoric acid and its Cs salts using the TPD of ethanol and TPD of n-butyl amines (Verdes et al. 2012) and for studying the acidities of different Cs salts of molybdophosphoric acid supported on SBA-15 or Co salts of molybdophosphoric acid supported on modified mesoporous silica using the TPD of ammonia (Popa et al. 2014, 2018).

Generally, the strength of acid sites is related to the corresponding desorption temperature. Usually, the acid sites at $150-300{ }^{\circ} \mathrm{C}$ are defined as weak, at $300-450{ }^{\circ} \mathrm{C}$ as medium and at $450-600^{\circ} \mathrm{C}$ as strong acid sites (Jing et al. 2013) However, this is not standardized in the literature, for example, from Sundaramurthy et al. (2008) the acid sites are classified into the weak $\left(\leq 200{ }^{\circ} \mathrm{C}\right)$, medium or moderate $\left(200-350{ }^{\circ} \mathrm{C}\right)$ and strong $\left(\geq 350{ }^{\circ} \mathrm{C}\right)$ acid sites. In this study, the desorbed amount of $\mathrm{NH}_{3}$ at temperatures below $(260 \pm 30){ }^{\circ} \mathrm{C}$ was defined as the number of weak acid sites and above this temperature as the number of strong acid sites.

For pure AgPW (Fig. 4, step 4) two $\mathrm{NH}_{3}$ desorption steps were observed that were ascribed to weak, medium or strong acidic sites, and a third step which is a decomposition peak. The $\mathrm{NH}_{3}$ desorption for $\mathrm{AgPW}$ exhibits the first desorption rate maximum at $173{ }^{\circ} \mathrm{C}$ (weak acidic sites) while the second desorption rate maximum at $407^{\circ} \mathrm{C}$ (strong acidic sites) is observed on the DTG curve, accompanied by two endothermic peaks on the DTA curve. The third desorption peak is observed at $578{ }^{\circ} \mathrm{C}$ and is ascribed to the decomposition of the AgPW salt.

The TG, DTG and DTA curves in the TPD- $\mathrm{NH}_{3}$ region for the non-isothermal heating in the range of $100-600{ }^{\circ} \mathrm{C}$ for $\beta$ zeolite and composites are shown in Fig. 5.

Following previously mentioned, $\beta$ zeolite profile has two desorption peaks ascribed to weak and strong acidic sites, and a third, small desorption step which could be related to acidic sites that arise from surface hydroxyl groups attached to $\mathrm{Si}$ and $\mathrm{Al}$, Fig. $5 \mathrm{~d}$.

The $\beta$ AgPW-WI and $\beta$ AgPW-IE composites, Fig. $5 \mathrm{a}, \mathrm{b}$, have a thermal and adsorption-desorption behavior almost identical to $\beta$ zeolite, while in $\beta \mathrm{AgPW}-\mathrm{DM}$, Fig. $5 \mathrm{c}$, the properties of both precursors, zeolite and AgPW, can be differentiated.

The subtraction of mass loss for TPD of water from the mass loss for TPD of ammonia in water gives the amount of $\mathrm{NH}_{3}, W(\mathrm{mg})$, that corresponds, stoichiometrically, to acidity. The acidity of a sample, reported in units of millimoles of acid sites per gram of sample, is calculated by the following formula:
Acidity $=W(\mathrm{mg}) \times \frac{\left(\frac{1}{17 \mathrm{gmol}^{-1}}\right)}{m_{\text {pretr. }}(\mathrm{g})}$

where $m_{\text {pretr. }}$ is the mass of the sample after pre-treatment (see experimental part for details). The calculated results are presented in Table 1.

The total acidity $\left(\mathrm{mmol} \mathrm{g}^{-1}\right)$ of pure AgPW salt is increased when it was supported on $\beta$ zeolite, which contains the highest portion of weak acid sites and considerable overall acidity. Further on, the amount and distribution of acid sites and their strength in $\beta / \mathrm{AgPW}$ composites are significantly influenced by acidic properties of the $\beta$ support. Composite samples have strong sites density and total acidity higher in comparison to the pure AgPW salt. For $\beta \mathrm{AgPW}-\mathrm{WI}$ and $\beta \mathrm{AgPW}-\mathrm{IE}$ composites, densities ascribed to strong acidic sites are higher than for $\beta$ zeolite, which could be related to a synergetic effect induced by cumulative strong acidic sites generated by the presence of welldispersed Keggin ions on the zeolite network. It has been shown earlier that the dispersion of heteropoly acid on the zeolites is an effective way to improve the accessibility of their acid sites (Freitas et al. 2018). For this reason, we found that an adequate $\mathrm{AgPW}$ dispersion over the zeolite surface is crucial to increase the acidity in the composites.

There is an exception of $\beta$ AgPW-DM composites, which have both, strong sites density and total acidity lower than $\beta$ zeolite has, which is in accordance with the previous characterization, pointing to unsupported salt phase in the material prepared by dry mixing. Composite preparation procedures induced minor effects on the weak acid sites, on the other hand, strong acid sites were affected significantly which led to overall acidity rising, in comparison to AgPW.

\section{Catalytic study}

Composite samples with a higher content of strong acid centers ( $\beta \mathrm{AgPW}-\mathrm{WI}$ and $\beta \mathrm{AgPW}-\mathrm{IE}$ ) exhibited higher conversion compared to the composite with a lower proportion of strong acid sites, $\beta \mathrm{AgPW}$-DM. $\beta \mathrm{AgPW}$-IE has retained a conversion over $81 \%$ while $\beta \mathrm{AgPW}-\mathrm{WI}$ after $700 \mathrm{~min}$ of reaction has significant $86 \%$ (Fig. 6) which is the best result ever obtained for Ag-containing heteropolyacids alone and anchored to various carriers (Holclajtner-Antunović et al. $2015 b)$. An interesting result is the inflection point before $350 \mathrm{~min}$, when conversion in the presence of $\beta \mathrm{AgPW}$-WI remains constant and stable, while one recorded for $\beta A g P W-I E$ descends below $\beta A g P W-W I$, even though it was slightly higher at the beginning of the reaction (98\%). A possible reason for the ethanol conversion decreases with time on stream is the cokes formation which leads to blocking the acidic centers responsible for ethylene formation (Popa et al. 2018; Verdes et al. 2019). Introduction of Ag leads to 
Fig. 5 The TG, DTA and DTG curves in TPD- $\mathrm{NH}_{3}$ region: a $\beta A g P W-W I, \quad b \quad \beta A g P W-I E, \mathbf{c}$ $\beta$ AgPW-DM and $\mathbf{d} \beta$ zeolite (a)

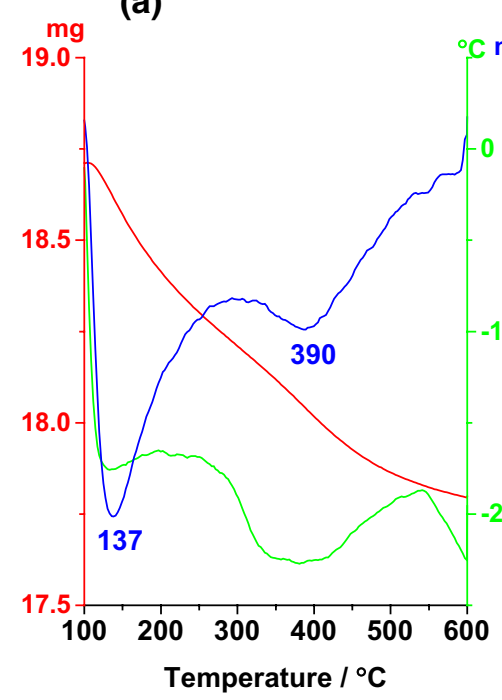

(c)

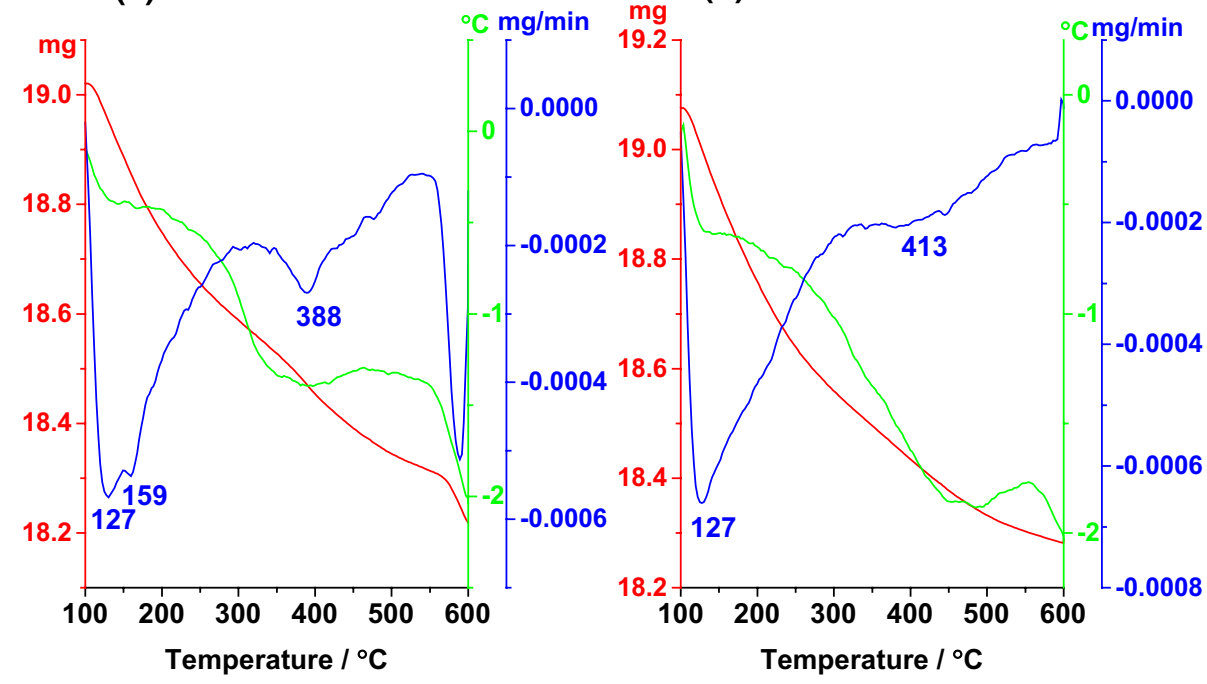

Table 1 The mass loss for TPD- $\mathrm{NH}_{3}$ and calculated acidity of samples

\begin{tabular}{|c|c|c|c|c|c|}
\hline Sample & Mass loss I (mg) & Mass loss II (mg) & $\begin{array}{l}\text { Weak acid } \\
\text { site density } \\
\left(\mathrm{mmol} \mathrm{g}^{-1}\right)\end{array}$ & $\begin{array}{l}\text { Strong acid } \\
\text { site density } \\
\left(\mathrm{mmol} \mathrm{g}^{-1}\right)\end{array}$ & $\begin{array}{l}\text { Total acidity } \\
\left(\mathrm{mmol} \mathrm{g}^{-1}\right)\end{array}$ \\
\hline$\beta$ & 0.4413 & 0.3288 & 1.42 & 1.05 & 2.47 \\
\hline $\mathrm{AgPW}$ & 0.3238 & 0.2734 & 0.96 & 0.81 & 1.78 \\
\hline$\beta A g P W-W I$ & 0.4044 & 0.4775 & 1.32 & 1.56 & 2.88 \\
\hline$\beta A g P W-I E$ & 0.3966 & 0.5193 & 1.35 & 1.77 & 3.12 \\
\hline$\beta A g P W-D M$ & 0.3781 & 0.3109 & 1.21 & 0.99 & 2.20 \\
\hline
\end{tabular}

increase in conversion stability when compared to pure HPW acid, although the initial value for acid (87\%) is much higher than for salt (47\%), after $300 \mathrm{~min}$ it drops below $50 \%$, as seen previously in the contribution by Holclajtner-Antunović et al. (2015a). The decrease in conversion in the $\beta \mathrm{AgPW}$-IE sample is directly related to the less efficient formation of Ag salt, i.e., the presence of HPW on the zeolite surface. The portion of isolated protons from HPW is also indicated 
(a)

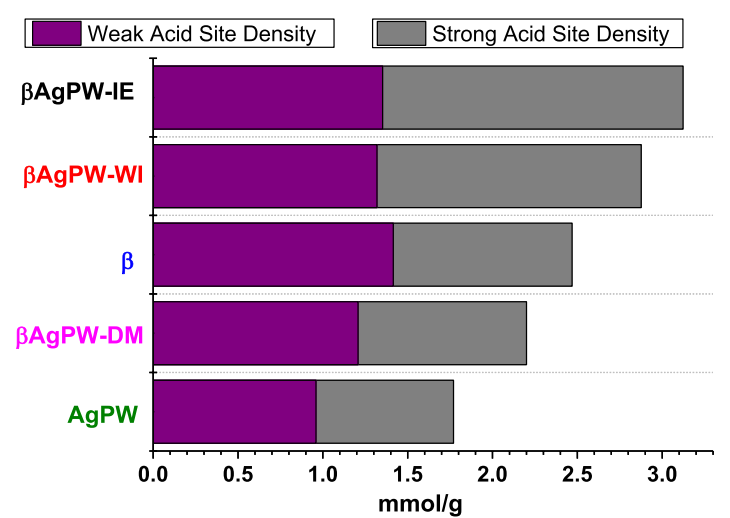

(c)

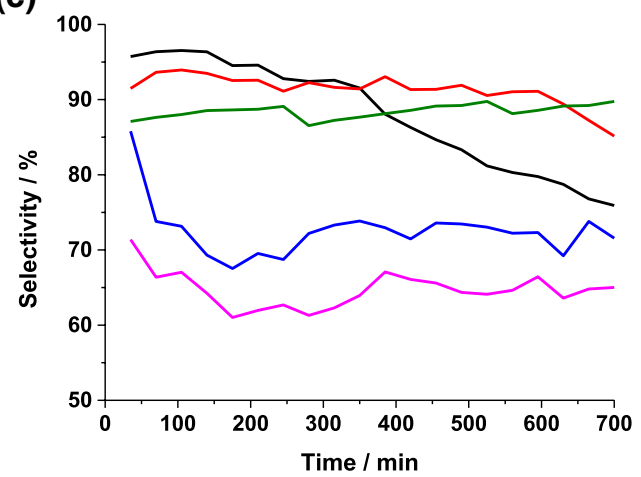

(b)

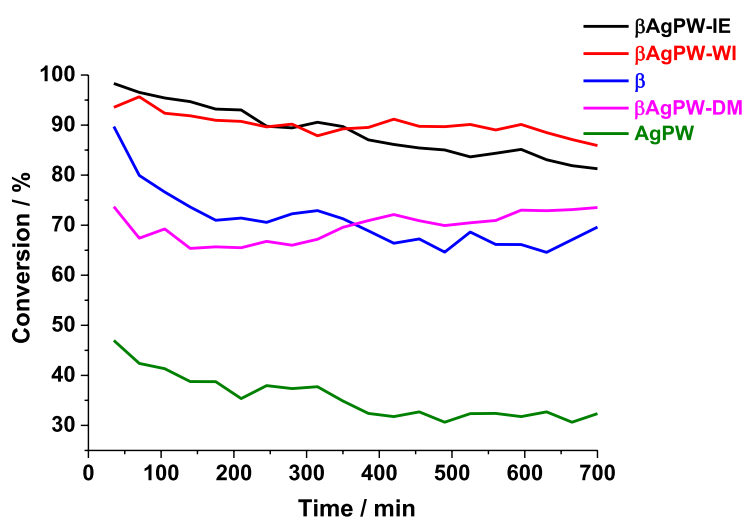

(d)

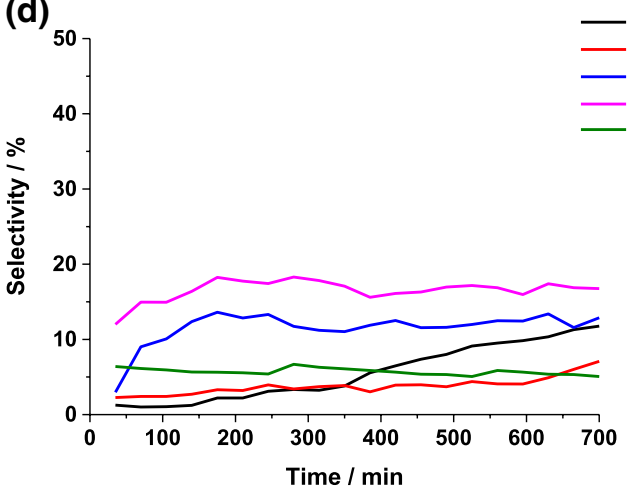

Fig. 6 a The graphic view of weak and strong acid site density, b Ethanol conversion c Selectivity of ethylene, and d Selectivity of diethyl ether vs. time of streaming obtained at $300^{\circ} \mathrm{C}$

by the higher density of strong acid sites in $\beta$ AgPW-IE than in $\beta$ AgPW-WI composite. Lower efficiency in ethylene production can be seen for $\beta \mathrm{AgPW}-\mathrm{DM}$ and pure $\beta$ zeolite 73.5-69.6\%. Inflection is also seen in the corresponding moment, the middle of the monitored reaction period when $\beta A g P W-D M$ samples achieve higher conversion than pure $\beta$ zeolite. This moment can be regarded as a point when present $\mathrm{Ag}$ ions become dominant conversion sites in the investigated materials.

A curiosity seen in this reaction is that HPW itself is found to be more efficient catalyst than its Ag salt form only during the first $100 \mathrm{~min}$ of the reaction after that conversion drops significantly (Holclajtner-Antunović et al. 2015a). What's more, supporting increases conversion efficiency and selectivity when both HPW (Jović et al. 2017) and AgPW (Holclajtner-Antunović et al. 2015a) are in question. The advantage of impregnation procedure for preparation of $\beta \mathrm{AgPW}-\mathrm{WI}$ material is clearly seen in selectivity assessment. The highest selectivity toward ethylene production, stable over a reaction period of $700 \mathrm{~min}$, is observed for the $\beta$ AgPW-WI sample. Takahara et al. (2005) reported that ethylene yield is substantial in the presence of stronger acid sites, while ether production occurs on the weak sites. Again, as the $\beta A g P W-W I$ sample has significant, but not the highest, detected share of strong acid sites (found for $\beta \mathrm{AgPW}-\mathrm{IE}$ ), a conclusion can be drawn-distribution and presence of $\mathrm{AgPW}$ active phase is crucial for both stable conversion and high selectivity results in ethylene production.

The observed high catalytic activity of $\beta \mathrm{AgPW}$ composites is attributed to the presence of both Brønsted and Lewis acid sites. Solid tungstophosphoric acid $\left(\mathrm{H}_{3} \mathrm{PW}_{12} \mathrm{O}_{40}\right)$ and its acidic salts are pure Brønsted acids (Luzgin and Stepanov 2014), but the acidic properties of heteropoly salts in the solid-state are sensitive to counter-cations. Since the $\mathrm{Ag}_{3} \mathrm{PW}_{12} \mathrm{O}_{40}$ salt is neutral, its catalytic activity is due to the Lewis acidity (Misono 1987), or the salt may also contain the residual protons in the solid lattice. The presence of protons in the $\mathrm{H} \beta$ zeolite is related to Brønsted acidity. According to Kito-Borsa and Cowley, the dehydration of ethanol to ethylene requires two adjacent Lewis acid sites or a strong Brønsted acid site, while the dehydration of ethanol to diethyl ether requires only a single Lewis acid site (KitoBorsa and Cowley 2004), pointing to our results in this reaction as experimental evidence for the type of acid centers present in the AgPW/ $\beta$ composites. Protons present in the zeolite part of the composite are consumed when engaged 
in interaction with the Keggin ion, while they are available to ethanol molecule as Brønsted sites only when they are not engaged in interaction with a polyanion. These unaffected zeolite protons give rise to Brønsted acidity which accompanies Lewis sites of the AgPW phase, thus producing highly efficient composite catalysts in ethanol dehydration.

Although significant endeavor and improvement in ethylene production research are made, in order to meet all the needs for this precursor we are still lacking in the fossil fuels processing area as there is no new method that could replace current procedures on an industrial scale. Current efforts for accomplishing low reaction temperatures and substantial ethylene yield in catalytic processes have discovered a considerable number of materials that may find application in industry, where promising ones are definitely zeolites and heteropoly compounds (Fan et al. 2013). Recently, Wu proposed that ZSM-5 catalyst dealumination results in its upgraded catalytic performance in ethanol dehydration at low temperature (Wu and $\mathrm{Wu}$ 2017). Matachowski et al. (2012) published that AgPW salt is considered to be an environmentally friendly catalyst with perspective in industrial implementation for ethylene production under mild experimental conditions (Gurgul et al. 2011). The ability of our new $\beta \mathrm{AgPW}$ composites to catalyze the dehydration of ethanol to ethylene at relatively low temperatures $\left(300^{\circ} \mathrm{C}\right)$, with stable conversion and high selectivity, as well as low cost due to the small proportion of the active phase, has made it potentially commercially valuable.

\section{Conclusion}

This work deals with the preparation, characterization and catalytic application of hybrid materials consisting of the silver salt of dodecatungstophosphoric acid ( $\mathrm{AgPW})$ and $\beta$ zeolite. The complete formation of neutral $\mathrm{AgPW}$ salt, homogeneously dispersed on the surface of the zeolite, both in wet-impregnated and ion-exchanged $\beta \mathrm{AgPW}$ composites, was confirmed. Keggin anion distortion occured as a consequence of the interaction between oxygen atoms in heteropoly anion and extra-framework cations, $\mathrm{H}^{+}$or $\mathrm{Ag}^{+}$, on the $\beta$ zeolite surface, in composites prepared by two-steps wet impregnation and ion-exchange procedures, while dry mixture of $\beta$ zeolite and $\mathrm{AgPW}$ provided no interaction in the absence of solvents during the synthesis.

Composite preparation procedures induced a minor effect on the weak acid sites, while strong acid sites were increased significantly, and $\beta / \mathrm{AgPW}$ composites have strong acid sites density and total acidity higher in comparison to the pure AgPW salt. For wet-impregnated and ion-exchanged composites, densities ascribed to strong acidic sites are higher than found for $\beta$ zeolite, which is related to a synergetic effect induced by cumulative strong acidic sites generated by the presence of well-dispersed Keggin ions on the zeolite network.

The catalytic performance of the composites was tested in ethanol dehydration where samples with higher content of strong acid centers exhibited higher conversion compared to composite with a lower proportion of strong acid sites, obtained by dry mixing. The ion-exchanged $\beta$ AgPW sample has attained a conversion over $81 \%$, while the wet-impregnated sample has significant $86 \%$, which is the best result ever reported for Ag-containing heteropolyacids alone and anchored to various carriers.

The advantage of the impregnation procedure for composite preparation is found to be crucial for selectivity toward ethylene production. Concerning all comprehensive findings, this work proved that distribution and presence of $\mathrm{AgPW}$ active phase is crucial for both stable conversion and high selectivity results in ethylene production from ethanol, which is regarded as one of the most significant processes in environmental and sustainable industrial chemistry.

Acknowledgements The financial support by Ministry of Education, Science and Technological Development of Republic of Serbia (Contract number: 451-03-68/2020-14/200146 and 451-03-68/2020-14200161) and by Romanian Academy Project No. 4.3. The authors are grateful to Prof. Dr. Slavko Mentus from University of Belgrade-Faculty of Physical Chemistry for DTA-TG measurements. The authors would like to thank the Laboratory of Neutron Physics, Sector of Raman Spectroscopy Center Nanobiophotonics at Joint Institute for Nuclear Research, Dubna, Russia for providing AFM measurements.

\section{References}

Austin N, Kostetskyy P, Mpourmpakis G (2018) Design of highly selective ethanol dehydration nanocatalysts for ethylene production. Nanoscale 10:4004-4009. https://doi.org/10.1039/c7nr0 $8678 \mathrm{~d}$

Bajuk-Bogdanović D, Jović A, Nedić Vasiljević B et al (2017) 12-Tungstophosphoric acid/BEA zeolite composites - Characterization and application for pesticide removal. Mater Sci Eng B 225:6067. https://doi.org/10.1016/J.MSEB.2017.08.011

Clemente MCH, Valadares DS, Lacava AB et al (2019) Catalytic transformation conditions of ethanol on dealuminated BEA zeolites. J Braz Chem Soc 30:2182-2190. https://doi.org/10.21577/01035053.20190109

De Oliveira M, Rodrigues-Filho UP, Schneider J (2014) Thermal transformations and proton species in 12-phosphotungstic acid hexahydrate studied by $1 \mathrm{H}$ and $31 \mathrm{P}$ solid-state nuclear magnetic resonance. J Phys Chem C 118:11573-11583. https://doi.org/10.1021/ jp501887x

Fan D, Dai DJ, Wu HS (2013) Ethylene formation by catalytic dehydration of ethanol with industrial considerations. Materials (Basel) 6:101-115. https://doi.org/10.3390/ma6010101

Flanigen EM, Khatami H, Szymanski HA (1974) Infrared structural studies of zeolite frameworks. In: Flanigen EM (ed) Molecular sieve zeolites-I. American Chemical Society, pp 201-229

Freitas EF, Araújo ÁAL, Paiva MF et al (2018) Comparative acidity of BEA and Y zeolite composites with 12-tungstophosphoric 
and 12-tungstosilicic acids. Mol Catal 458:152-160. https://doi. org/10.1016/j.mcat.2018.03.005

Gallo JMR, Bueno JMC, Schuchardt U (2014) Catalytic transformations of ethanol for biorefineries. J Braz Chem Soc 25:2229-2243

Gurgul J, Zimowska M, Mucha D et al (2011) The influence of surface composition of Ag3PW12O 40 and Ag3PMo12O40 salts on their catalytic activity in dehydration of ethanol. J Mol Catal A Chem 351:1-10. https://doi.org/10.1016/j.molcata.2011.09.016

Holclajtner-Antunović I, Bajuk-Bogdanović D, Popa A et al (2015a) Structural, morphological and catalytic characterization of neutral Ag salt of 12-tungstophosphoric acid: influence of preparation conditions. Appl Surf Sci 328:466-474. https://doi.org/10.1016/j. apsusc.2014.12.062

Holclajtner-Antunović I, Bajuk-Bogdanović D, Popa A et al (2015b) Preparation, characterization and catalytic activity of mesoporous Ag2HPW12O40/SBA-15 and Ag2HPW12O40/TiO2 composites. Mater Chem Phys 160:359-368. https://doi.org/10.1016/j.match emphys.2015.04.052

Janićijević D, Uskoković-Marković S, Ranković D et al (2020) Double active BEA zeolite/silver tungstophosphates - Antimicrobial effects and pesticide removal. Sci Total Environ 735:139530. https ://doi.org/10.1016/j.scitotenv.2020.139530

Jevremović A, Bober P, Mičušík M et al (2019) Synthesis and characterization of polyaniline/BEA zeolite composites and their application in nicosulfuron adsorption. Microporous Mesoporous Mater 287:234-245. https://doi.org/10.1016/j.micro meso.2019.06.006

Jevremović A, Božinović N, Arsenijević D et al (2020) Modulation of cytotoxicity by consecutive adsorption of tannic acid and pesticides on surfactant functionalized zeolites. Environ Sci Process Impacts 22:2199-2211. https://doi.org/10.1039/D0EM00251H

Jing F, Katryniok B, Bordes-Richard E, Paul S (2013) Improvement of the catalytic performance of supported (NH4) 3HPMo11VO40 catalysts in isobutane selective oxidation. In: Catalysis Today. Elsevier, Amsterdam, pp 32-39

Jović A, Bajuk-Bogdanović D, Nedić Vasiljević B et al (2017) Synthesis and characterization of 12-phosphotungstic acid supported on BEA zeolite. Mater Chem Phys 186:430-437. https://doi. org/10.1016/j.matchemphys.2016.11.015

Jović A, Milikić J, Bajuk-Bogdanović D et al (2018) 12-phosphotungstic acid supported on BEA zeolite composite with carbonized polyaniline for electroanalytical sensing of phenols in environmental samples. J Electrochem Soc 165:H1013-H1020. https:// doi.org/10.1149/2.0021816jes

Kito-Borsa T, Cowley S (2004) Kinetics, characterization and mechanism for the selective dehydration of ethanol to diethyl ether over solid acid catalysts. In: ACS division of fuel chemistry, preprints

Kunkeler PJ, Zuurdeeg BJ, Van Der Waal JC et al (1998) Zeolite beta: the relationship between calcination procedure, aluminum configuration, and Lewis acidity. J Catal 180:234-244

Luzgin MV, Stepanov AG (2014) Solid-state NMR characterization of brønsted acid sites of cesium salt of 12-tungstophosphoric acid. J Phys Chem C 118:21042-21048. https://doi.org/10.1021/jp507 $034 b$

Madeira FF, Gnep NS, Magnoux P et al (2009) Ethanol transformation over HFAU, HBEA and HMFI zeolites presenting similar Brønsted acidity. Appl Catal A Gen 367:39-46. https://doi. org/10.1016/j.apcata.2009.07.033

Matachowski L, Zimowska M, Mucha D, Machej T (2012) Ecofriendly production of ethylene by dehydration of ethanol over Ag 3PW $12 \mathrm{O} 40$ salt in nitrogen and air atmospheres. Appl Catal B Environ 123-124:448-456. https://doi.org/10.1016/j.apcatb.2012.05.003

Milojević-Rakić M, Bajuk-Bogdanović D, Nedić Vasiljević B et al (2018) Polyaniline/FeZSM-5 composites-synthesis, characterization and their high catalytic activity for the oxidative degradation of herbicide glyphosate. Microporous Mesoporous Mater 267:68-79. https://doi.org/10.1016/j.micro meso.2018.03.019

Milojević-Rakić M, Janošević A, Krstić J et al (2013) Polyaniline and its composites with zeolite ZSM-5 for efficient removal of glyphosate from aqueous solution. Microporous Mesoporous Mater 180:141-155. https://doi.org/10.1016/j.micromeso.2013.06.025

Mioč U, Todorović M, Davidović M et al (2005) Heteropoly compounds-from proton conductors to biomedical agents. Solid State Ionics 176:3005-3017. https://doi.org/10.1016/j.ssi.2005.09.056

Mioč UB, Dimitrijević RZ, Davidović M et al (1994) Thermally induced phase transformations of 12-tungstophosphoric acid 29-hydrate: synthesis and characterization of PW8O26-type bronzes. J Mater Sci 29:3705-3718. https://doi.org/10.1007/ BF00357338

Misono M (1987) Heterogeneous catalysis by heteropoly compounds of molybdenum and tungsten. Catal Rev 29:269-321. https://doi. org/10.1080/01614948708078072

Nedić Vasiljević B, Obradović M, Bajuk-Bogdanović D et al (2019) In situ synthesis of potassium tungstophosphate supported on BEA zeolite and perspective application for pesticide removal. J Environ Sci 81:136-147. https://doi.org/10.1016/j.jes.2019.01.018

Okamoto K, Uchida S, Ito T, Mizuno N (2007) Self-organization of allinorganic dodecatungstophosphate nanocrystallites. J Am Chem Soc 129:7378-7384. https://doi.org/10.1021/ja070694c

Popa A, Sasca V, Verdes O et al (2014) Acidic and neutral caesium salts of 12-molybdophosphoric acid supported on SBA-15 mesoporous silica. the influence of Cs concentration and surface coverage on textural and structural properties. Mater Res Bull 50:312-322. https://doi.org/10.1016/j.materresbull.2013.11.015

Popa A, Sasca V, Verdes O, Oszko A (2018) Preparation and catalytic properties of cobalt salts of Keggin type heteropolyacids supported on mesoporous silica. Catal Today 306:233-242. https ://doi.org/10.1016/j.cattod.2017.02.045

Ramasamy KK, Wang Y (2014) Ethanol conversion to hydrocarbons on HZSM-5: effect of reactionconditions and Si/Al ratio on the product distributions. Catal Today 237:89-99. https://doi. org/10.1016/j.cattod.2014.02.044

Ratajczak H, Barnes AJ, Bielański A et al (2001) Vibrational spectroscopy of heteropoly acids. Polyoxometalate chemistry from topology via self-assembly to applications. Kluwer Academic Publishers, Dordrecht, pp 101-116

Rocchiccioli-Deltcheff C, Fournier M, Franck R, Thouvenot R (1983) Vibrational investigations of polyoxometalates. 2. Evidence for anion-anion interactions in molybdenum(VI) and tungsten(VI) compounds related to the Keggin structure. Inorg Chem 22:207216. https://doi.org/10.1021/ic00144a006

Rosenheim A, Jaenicke J (1917) Zur Kenntnis der Iso- und Heteropolysäuren. XV. Mitteilung Über Heteropolywolframate und einige Heteropolymolybdänate. Zeitschrift für Anorg und Allg Chemie 101:235-275. https://doi.org/10.1002/zaac.19171010106

Sasca V, Avram L, Verdes O, Popa A (2010) The n-butyl amine TPD measurement of Brönsted acidity for solid catalysts by simultaneous TG/DTG-DTA. Appl Surf Sci 256:5533-5538. https://doi. org/10.1016/j.apsusc.2009.12.131

Sundaramurthy V, Eswaramoorthi I, Dalai AK, Adjaye J (2008) Hydrotreating of gas oil on SBA-15 supported NiMo catalysts. Microporous Mesoporous Mater 111:560-568. https://doi.org/10.1016/j. micromeso.2007.08.037

Takahara I, Saito M, Inaba M, Murata K (2005) Dehydration of ethanol into ethylene over solid acid catalysts. Catal Letters 105:249-252. https://doi.org/10.1007/s10562-005-8698-1

Van Bekkum H, Flanigen EM, Jacobs PA, Jansen JC (2001) Introduction to zeolite science and practice: Preface 2nd edition. In: Studies in surface science and catalysis, 2nd edn. Elsevier Science, Amsterdam, pp ix-X 
Verdes O, Avram L, Popa A, Sasca V (2012) The adsorption/desorption of ethanol on Cs x H 3-x PW 12 O 40 by TG/DTG-DTA analysis. J Optoelectron Adv Mater 14:537-543

Verdes O, Sasca V, Popa A et al (2019) Catalytic activity of heteropoly tungstate catalysts for ethanol dehydration reaction: Deactivation and regeneration. Catal Today. https://doi.org/10.1016/j.catto d.2019.12.040

Wu CY, Wu HS (2017) Ethylene formation from ethanol dehydration using ZSM-5 catalyst. ACS Omega 2:4287-4296. https://doi. org/10.1021/acsomega.7b00680
Zhang M, Yu Y (2013) Dehydration of ethanol to ethylene. Ind Eng Chem Res 52:9505-9514

Publisher's Note Springer Nature remains neutral with regard to jurisdictional claims in published maps and institutional affiliations.

\section{Authors and Affiliations}

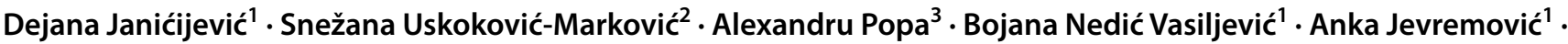 Maja Milojević-Rakić ${ }^{1}$ Danica Bajuk-Bogdanović ${ }^{10}$}

Danica Bajuk-Bogdanović

danabb@ ffh.bg.ac.rs

1 University of Belgrade - Faculty of Physical Chemistry, Studentski trg 12-16, 11158 Belgrade, Serbia
2 University of Belgrade - Faculty of Pharmacy, Vojvode Stepe 450, 11221 Belgrade, Serbia

3 Institute of Chemistry Timisoara, B1. Mihai Viteazul 24, 300223 Timisoara, Romania 